\title{
High-Efficiency and High-Power Vertical-Cavity Surface-Emitting Laser Designed for Cryogenic Applications
}

\author{
Bo Lu, Wen-Lin Luo, C. Hains, Julian Cheng, Senior Member, IEEE, R. P. Schneider, R. P. Choquette,
} K. L. Lear, Member, IEEE, S. P. Kilcoyne, and J. C. Zolper, Member, IEEE

\begin{abstract}
We report the first vertical-cavity surface-emitting laser (VCSEL) that has been optimized for cryogenic applications near $77 \mathrm{~K}$, with superior characteristics that include a highoutput power $\left(P_{\text {out }}=22 \mathrm{~mW}\right.$ at $\left.I=25 \mathrm{~mA}\right)$, high power conversion efficiency $\left(\eta_{d}=32 \%\right)$, low threshold voltage $\left(V_{\text {th }}=\right.$ $1.75 \mathrm{~V})$ and current $\left(I_{\mathrm{th}}=1.7 \mathrm{~mA}\right)$, and low power dissipation $\left(9 \mathrm{~mW}\right.$ at $P_{\text {out }}=\mathbf{2 . 0} \mathrm{mW}$ ) for a 20 - $\mu \mathrm{m}$-diameter device.
\end{abstract}

$\mathbf{T}$ HE DEVELOPMENT of vertical-cavity surface-emitting lasers (VCSEL's) has made great strides in recent years, having achieved excellent room-temperature operating characteristics, including a very low threshold current density $\left(400 \mathrm{~A} / \mathrm{cm}^{2}\right)$ [1], [2] and low threshold voltage $(1.6 \mathrm{~V})$ [3], a low series resistance $(<20 \Omega)$ [4], thermally stable electrical characteristics [4], and a high-power conversion efficiency (21\%) [5]. However, the room-temperature operation of VCSEL's is generally limited by its relatively small slope efficiency $\left(\eta_{s}<35 \%\right)$ and low output power ( $P_{\text {out }}<10 \mathrm{~mW}$ for a $20-\mu \mathrm{m}$-diameter device). It has been observed (Fig. 1) that the slope efficiency and the output power of proton-implant-isolated AlGaAs-GaAs VCSEL's improve dramatically as the temperature is decreased, with $\eta_{s}$ approaching $100 \%$ at $77 \mathrm{~K}$, and $P_{\text {out }}>20 \mathrm{~mW}$. This suggests that VCSEL's with superior performance can be achieved at cryogenic temperatures, including a higher wallplug efficiency and higher output power, and very low power dissipation. Such a VCSEL would be well suited as a lowpower source for a high-speed optical data link operating at cryogenic temperatures, which could be used, for example, as a read-out link for a focal-plane array in satellite and space imaging applications [6] in which power dissipation must be kept to a minimum.

To achieve low power consumption $\left(P_{d}\right)$ and high power conversion efficiency $\left(\eta_{\text {eff }}\right)$, the VCSEL must have a very low threshold current $\left(I_{\mathrm{th}}\right)$ and a low operating voltage $(\mathrm{V})$, in addition to a high slope efficiency $\left(\eta_{s}\right)$. The former is achieved by designing the VCSEL so that optimal alignment of its lasing

Manuscript received November 29, 1994; revised January 25, 1995. This work was supported in part by AFOSR and the DOE under Contract No. DE-AC04-94AL85000.

B. Lu, W.-L. Luo, C. Hains, and J. Cheng are with the University of New Mexico, Center for High Technology Materials, Albuquerque, NM 87131 USA.

R. P. Schneider, K. L. Lear, S. P. Kilcoyne, and J. C. Zolper are with the Sandia National Laboratories, Albuquerque, NM 87185 USA.

IEEE Log Number 9410462 .

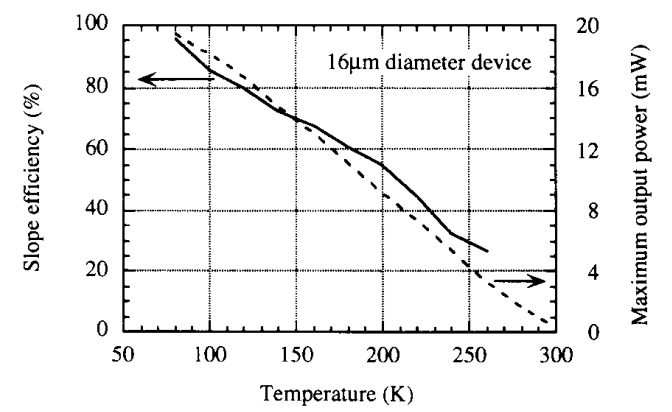

Fig. 1. The temperature dependence of the differential slope efficiency and the maximum-output optical power of a VCSEL with a $16-\mu \mathrm{m}$ active area diameter.

mode and gain peak occurs at the desired low temperature [7]. The operating voltages are reduced by lowering the barrier height at the VCSEL mirror's hetero-interfaces, which become more prohibitive to carrier transport as the temperature is reduced, thereby resulting in a large increase in $V_{\mathrm{th}}$ [4]. Various grading and doping techniques have been successfully applied to reduce these barrier heights and thus produce low and thermally stable operating voltages. Using parabolic grading of the mirror heterointerfaces [8], a minimum barrier height has been achieved even at a low doping level $(5 \times$ $10^{17} / \mathrm{cm}^{3}$ ). In this paper we report the first VCSEL that has been optimized for operation at $77 \mathrm{~K}$, with characteristics that are superior to those of similar VCSEL's optimized for 300$\mathrm{K}$ operation. Very high output power $\left(P_{\text {out }}=22 \mathrm{~mW}\right.$ at $I=25 \mathrm{~mA})$, high power conversion efficiency $\left(\eta_{\mathrm{eff}}=32 \%\right.$ ), high slope efficiency $\left(\eta_{s}>75 \%, \eta_{s} \approx 100 \%\right.$ for some devices), low threshold voltage $\left(V_{\mathrm{th}}=1.75 \mathrm{~V}\right)$ and current $\left(I_{\mathrm{th}}=1.7 \mathrm{~mA}\right)$, low threshold current density $\left(540 \mathrm{~A} / \mathrm{cm}^{2}\right)$, and low power dissipation $\left(P_{d}<9 \mathrm{~mW}\right.$ at $\left.P_{\text {out }}=2.0 \mathrm{~mW}\right)$ have been achieved by a $20-\mu$ m-diameter device.

The VCSEL consists of a single-wavelength-thick optical cavity, which contains a four-quantum-well active layer sandwiched between two distributed Bragg reflectors (DBR's) with parabolically graded heterointerfaces grown by metalorganic chemical vapor deposition. The upper and lower DBR mirrors contain 25 pairs and 38.5 pairs of $\mathrm{Al}_{0.95} \mathrm{Ga}_{0.05} \mathrm{As}$ and $\mathrm{Al}_{0.25} \mathrm{Ga}_{0.75} \mathrm{As}$ quarter-wave layers, respectively, and the doping concentration is graded from $1 \times 10^{18} / \mathrm{cm}^{3}$ near the surface to $5 \times 10^{17} / \mathrm{cm}^{3}$ near the active layer. The cavity 


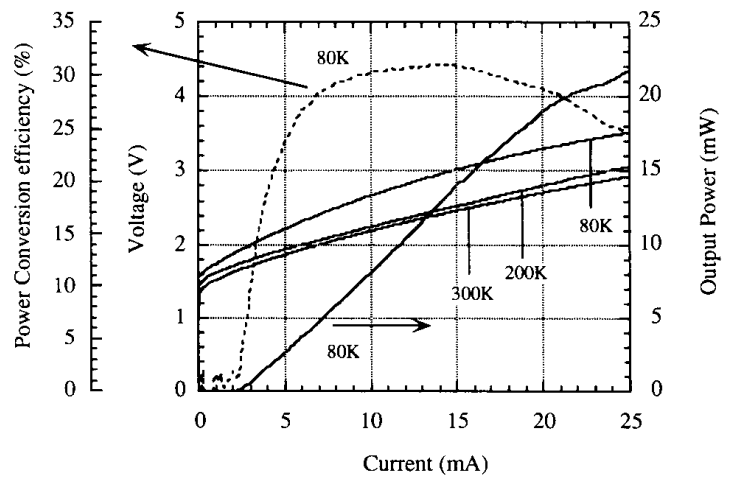

Fig. 2. The I-V characteristics of a $20-\mu \mathrm{m}$-diameter VCSEL at three different temperatures, and its L-I characteristic and power conversion efficiency at $80 \mathrm{~K}$ are shown.

mode $(810 \mathrm{~nm})$ is intentionally de-tuned from the gain peak $(850 \mathrm{~nm})$ at room temperature, and is aligned to the latter at $100 \mathrm{~K}$, where the lowest lasing threshold occurs [7]. Fig. 2 shows the current-voltage $(I-\mathrm{V})$ characteristics of a $20-\mu \mathrm{m}$ diameter device at three different temperatures $(80,200$, and $300 \mathrm{~K}$ ), and its light-current characteristic at $80 \mathrm{~K}$. The operating voltage at a fixed current level of $25 \mathrm{~mA}$ varies by only $0.7 \mathrm{~V}$ from $300 \mathrm{~K}$ to $80 \mathrm{~K}$, which indicates that a very low barrier height has been achieved at the DBR heterointerfaces by parabolic grading. At $80 \mathrm{~K}$, the threshold current and voltage are $2.2 \mathrm{~mA}$ and $1.8 \mathrm{~V}$, respectively, and the slope efficiency is $75 \%$ ( $\eta_{s} \approx 100 \%$ for some devices), and the maximum output power is $22 \mathrm{~mW}$ at $I=25 \mathrm{~mA}$. The light-current characteristic is linear up to a current level of almost $10 \times I_{\mathrm{th}}(22 \mathrm{~mA})$, and the slope efficiency is high $(\approx 75 \%)$. The power conversion efficiency is also shown in Fig. 2, which has a maximum of $32 \%$, and stays at a high level $\left(\eta_{\text {eff }}>28 \%\right.$ ) over a broad current range (from $7 \mathrm{~mA}$ to $22 \mathrm{~mA}$ ).

Fig. 3 shows the temperature dependence of $V_{\mathrm{th}}$ and $I_{\mathrm{th}}$. The voltages are low $(<2.4 \mathrm{~V})$ and, except for the temperature dependence of the bandgap, are relatively stable $(0.6 \mathrm{~V}$ change) over the entire temperature range from $80-300 \mathrm{~K}$, which is essential for low power dissipation. The minimum $I_{\mathrm{th}}$ of $1.7 \mathrm{~mA}\left(J_{\mathrm{th}}=540 \mathrm{~A} / \mathrm{cm}^{2}\right)$ is achieved at $100 \mathrm{~K}$ in accordance with our design. Fig. 4 shows the power dissipation of the VCSEL as a function of temperature at several constant optical output power levels, which also represents $\eta_{\text {eff }}=$ $P_{\text {out }} / P_{d}$ as a function of temperature and bias. At the optimum temperature $(100 \mathrm{~K})$, the power dissipation is $3 \mathrm{~mW}$ at threshold, $6 \mathrm{~mW}$ for $P_{\text {out }}=1 \mathrm{~mW}, 9 \mathrm{~mW}$ for $P_{\text {out }}=2.0 \mathrm{~mW}$, and $32 \mathrm{~mW}$ for $P_{\text {out }}=10 \mathrm{~mW}$ (with $\eta_{\text {eff }} \approx 30 \%$ ). The low power dissipation at low temperatures is a consequence of the low operating voltages and currents that have been achieved by design, and the high slope efficiency.

In conclusion, we have reported the first VCSEL's that were intentionally optimized for $77 \mathrm{~K}$ operation to take advantage of the high efficiency and high output power that can be achieved at low temperatures. Low threshold current density, very low power dissipation, high output power, and a high

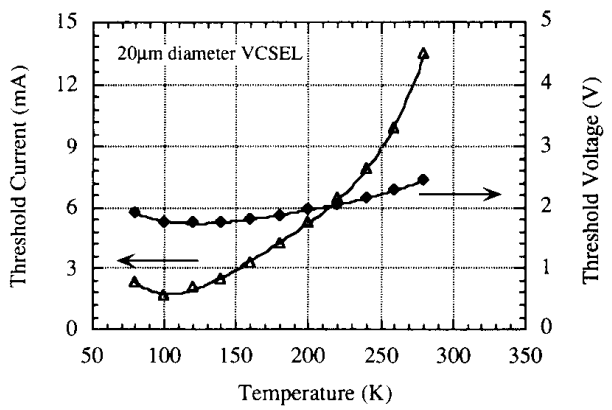

Fig. 3. Threshold current and voltage as a function of temperature, indicating small variation in $l_{\mathrm{th}}$ and optimum operation at $100 \mathrm{~K}$.

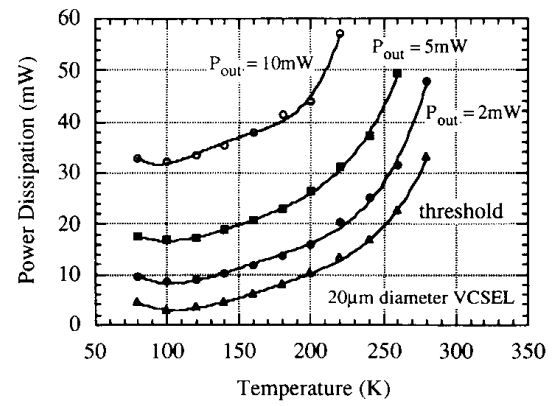

Fig. 4. Power dissipation of the VCSEL as a function of temperature at several constant optical output power levels.

power conversion efficiency have all been achieved in a single device, and exceed the characteristics of similar VCSEL's at $300 \mathrm{~K}$. With a value of $\eta_{s}$ approaching $100 \%$, a power conversion efficiency of greater than $50 \%$ is possible. These results confirm that the VCSEL is a suitable source for cryogenic optical link applications.

\section{REFERENCES}

[1] C. C. Hansing, H. Deng, D. L. Huffakes, D. G. Deppe, B. G. Streetman. and J. Sarathy, "Low-threshold continuous-wave surface emitting lasers with etched void confinement," IEEE Photon. Technol. Lett., vol, 6, pp. 320-322, 1994.

[2] T. Wipiejewski, K. Panzlaff, E. Zeeb, and K. J. Ebeling, "Tunable extremely low threshold vertical-cavity laser diodes," IEEE Photon. Technol. Lett., vol. 5, pp. 889-892, 1993.

[3] K. L. Lear, S. A. Chalmers, and K. P. Killeen, "Low threshold voltage vertical cavity surface-emitting laser," Electronics Lett., vol. 29, pp. 584-586, 1993.

[4] P. Zhou, B. Lu, J. Cheng, K. J. Malloy, S. Z. Sun, S. D. Hersee, and J. C. Zolpe, "Vertical-cavity surface-emitting lasers with thermally stable electrical characteristics," J. Appl. Phys. in press.

[5] K. L. Lear, R. P. Schneider, K. D. Choquette, S. P. Kilcoyne, J. J. Figiel, and J. C. Zolper, "Vertical cavity surface emitting lasers with $21 \%$ efficiency by metalorganic vapor phase epitaxy," IEEE Photon. Technol. Lett., vol. 6, pp. 778-780, 1994.

[6] A. R. Johnson, D. T. H. Liu, S. Forouhar, G. F.Lutes, J. Maserjian, and E. R. Fossum, "Optical links for cryogenic focal paln array," Optical Engineering, vol. 33, pp. 2013-2019. 1994.

[7] B. Lu, P. Zhou, J. Cheng, K. J. Malloy, and J. C. Zolper, "High temperature pulsed and continuous-wave operation and thermally stable threshold characteristics of vertical-cavity surface-emitting lasers grown by metalorganic chemical vapor deposition." Appl. Phys. Lett., vol. 65 , pp. 1337-1339, 1994

[8] E. F. Schubert, L. W. Tu, G. J. Zydik, R. F. Kopf, A. Benvenuti, and M. R. Pinto, "Elimination of heterojunction band discontinuities by modulation doping." Appl. Phys. Letl., vol. 60, pp. 466-468, 1992. 